\title{
Hypothesis on the pathogenesis of retinopathy of prematurity- it is not VEGF alone but anatomical structures that are crucial
}

\author{
Hans Pau
}

Received: 3 August 2009 /Accepted: 27 August 2009 /Published online: 17 September 2009

(C) Springer-Verlag 2009

In the light of new anti-neovascular treatments for proliferative retinal disorders, the question arises as to whether these treatments would be efficient for retinopathy of prematurity (ROP). While laser photocoagulation of the peripheral avascular areas can inhibit proliferation of the vessels into the vitreous, it is still unknown whether pure inhibition of the proliferative process by inhibition of vascular endothelial growth factor (VEGF) is sufficient and-even more relevant-does not damage the retinal structure or lead to contraction of vitreous strands with subsequent tractional detachment.

Some thoughts on the pathogenesis of retinopathy of prematurity and the pathogenesis of the avascular retina between demarcation line and tunica vasculosa lentis might help to highlight why anti-VEGF agents might not exert a long-term beneficial effect.

The pathogenesis of the demarcation line still remains obscure as does the factors that determine the time when the hyaloidal tissue attaching the retina disappears or the time when the growing retinal vessels reach the lens equator. While the current thinking mostly narrows the pathogenesis to an imbalance of growth factors as a consequence of relative hypoxia, there are embryological and anatomical reasons for the halt of retinal vascular proliferation at the demarcation line. Thus, a failure in apoptosis of the hyaloidal tissue that attaches the retina at

\section{H. Pau}

Department of Ophthalmology, University of Duesseldorf, Moorenstr. 5,

40255 Düsseldorf, Germany

\section{H. Pau $(\triangle)$}

Himmelgeister Landstraße 87,

40589 Düsseldorf, Germany

e-mail: Pauly@uni-duesseldorf.de the demarcation line could guide the outgrowth of pathologic retinal vessel into the vitreous. To the end, these anatomical thoughts might also explain why a lower birth weight puts children at a higher risk of late-stage ROP and why treatment with VEGF inhibitors may only cure part of the disease.

The hyaloidal vessel system arises partly from the lateral part of the tunica vasculosa lentis and attaches to the avascular retina between ora and equator (Fig. 1) [1]. The hyaloidal vessel system reaches its greatest development at approximately 10 weeks of gestation [12-14].

The hyaloidal vascular system appears to regress by apoptosis mostly between the 5th and 6th month of gestation and atrophy of the vasa hyaloidea propria is completed by 8 months [2-4]. By approximately 5 months, the retinal arcades have progressed to the equator of the eye. The retinal arteries are growing from the optic nerves towards the ora serrata and first reach the nasal periphery by 8 months $[5,6]$.

In premature infants, the growth of the retinal vasculature towards the equator coincides with the apoptosis of hyaloidal structures (vessels) attaching the retina at the demarcation line. If these mechanisms occur simultaneously, a demarcation line and later on a rim form. A major reason for the development of ROP might be the disbalance between the time of complete apoptosis of the embryonal hyaloidal tissue (vessels) and the premature growing of the retinal vessels.

In mature infants, the regression of the hyaloidal vessels is completed prior to the proliferation of the retinal vessels towards a "demarcation line". Ophthalmoscopically, the demarcation line represents a flat white line within the retinal plane and separates the avascular anterior "retinal" portion from the vascularized retina posteriorly. In the area of the vascularized retinal tissue the choroidal vessels are clearly visible through the retina. In contrast, the avascular anterior "retina" appears grayish-white in color without 
Fig. 1 a Hyaloidal blood vessels originating from the tunica vasculosa lentis attach to the retina between ora and equator. b Magnification x2. Approximately 2.5 months of gestation (with permission from Karger Publishers [1])
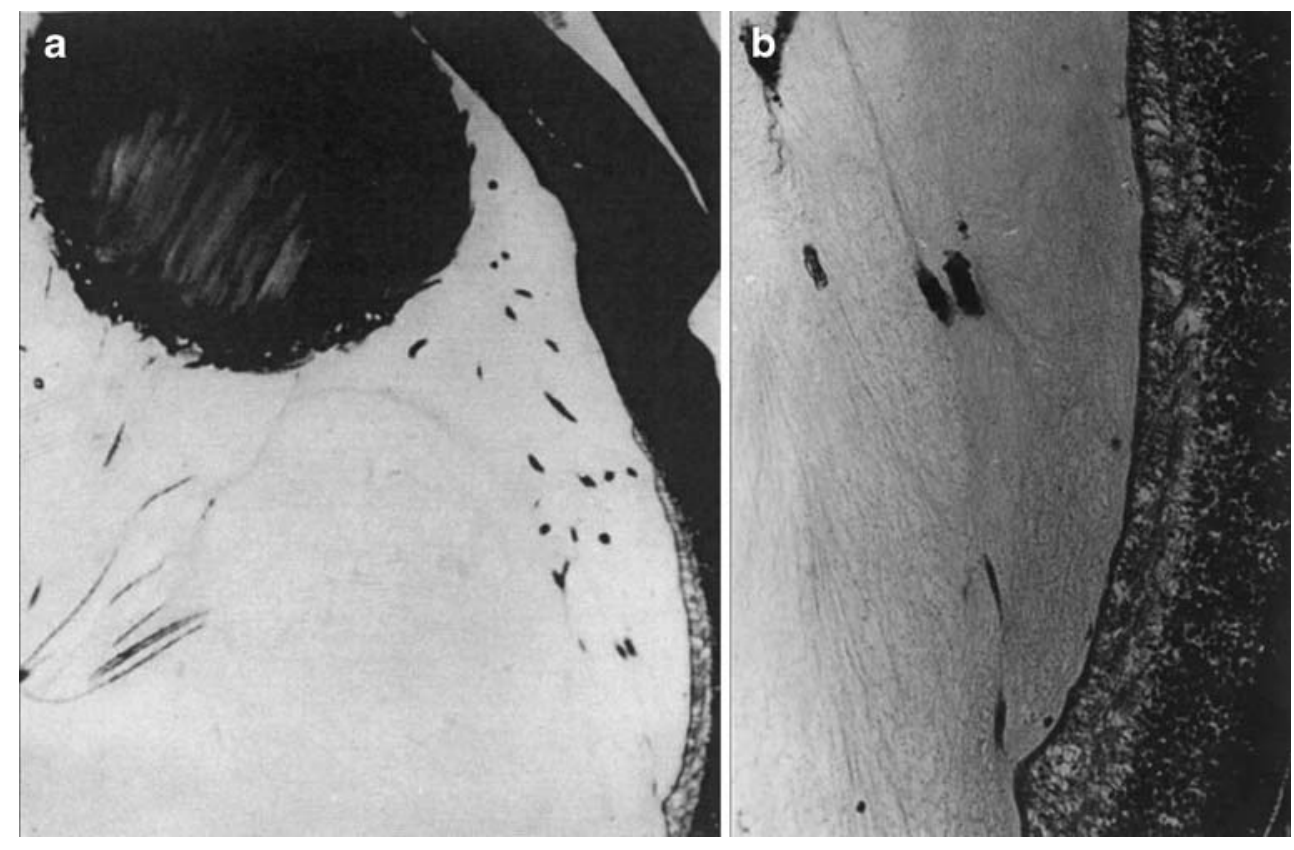

visible chorioidal vessels and extends from the demarcation line towards the lens. The avascular zone is characterized by an overlay of not yet apoptotic fetal hyaloidal structures, creating a mechanical barrier for the outgrowth of the retinal capillaries (Fig. 2)

Thus, the outgrowing retinal capillaries in ROP are halted at the demarcation line, which acts as a barrier consisting of the hyaloidal structures adherent to the retina

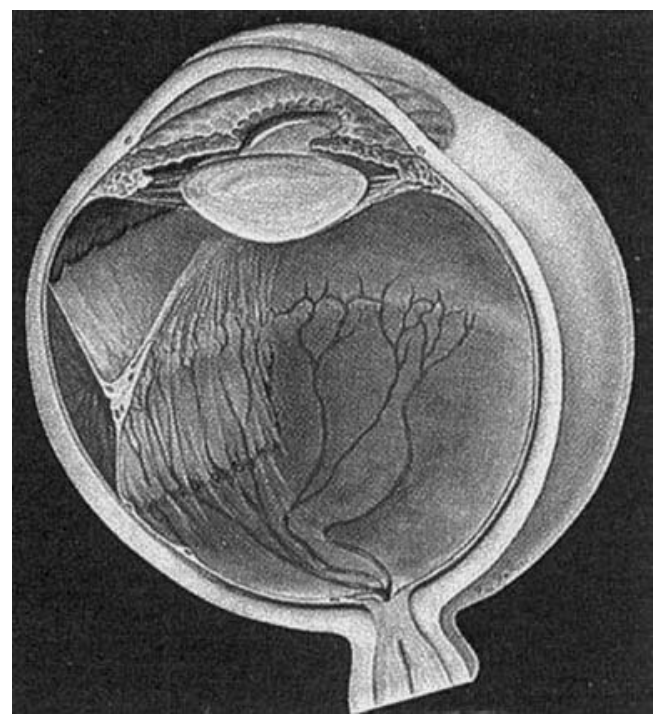

Fig. 2 Retinal vessels in ROP stage 4 topographically partly corresponding to earlier hyaloidal vessels coming from the tunica vasculosa lentis attaching the later demarcation line of the retina. Artist's sketch from the International Committee for Classification of the late stages of retinopathy (with permission from the American Medical Association [20]) that not disappear by apoptosis as they do in infants born at term. Moreover, the relative hypoxia of the avascular anterior part of the retina may results in a VEGFmediated abnormal dilation of the growth-arrested retinal vessels at the demarcation line that become abnormally branched and tortuous [6-8].

The surface of the residues of the peripheral hyaloidal structures (pseudo-retina) can act as a scaffold for the proliferating retinal vessels from the demarcation line towards the tunica vasculosa lentis (Fig. 2). As a result of the secondary contraction of these vascularized dense hyaloidal structures, a complete tractional retinal detachment can form. When later on the hyaloidal structures of the pseudo-retina disappear by apoptosis, the retinal vessels on the pseudo-retina may appear as an isolated band bridging the vitreous from the demarcation line towards the tunica vasculosa lentis (Fig. 2).

In the development of ROP, the major key risk factors are low birth weight and low gestational age. The relaxation of oxygen to the development of ROP is complex and not completely understood as are other risk factors [8].

In premature infants, many organ functions have to mature more rapidly than at normal birth. This is enhanced by the relative oxygen deficit. Thus in ROP the proliferation of the peripheral retinal vessels may be more rapid, while the hyaloidal structures have not yet undergone sufficient apoptosis. Thus, the lateral hyaloidal vessels are most important for the pathogenesis of ROP in the fetal eye. Histologically, these hyaloidal structures start relatively thick at the lateral part of the tunica vasculosa lentis and become increasingly narrow with a closer correlation to the retina and form the demarcation line at the point of 
insertion into the retina (Fig. 1). These lateral hyaloidal structures can be separated from the central vitreous by small membranes (Fig. 1). The larger the avascular zone of the retina the greater the risk of overgrowing retinal neovascularization with proliferation into the vitreous $[9,10]$. This supports the hypothesis that the lower the birth weight, the lower the regression of the hyaloidal structures attaching the retina. In a subgroup weighing less than $750 \mathrm{~g}$ at birth, $90 \%$ developed some degree of ROP [6, 8].

In normal adolescent eyes, the structure of the vitreous (membranelles, strands) corresponds to obliterated embryonal vasa hyaloidea [13]. Slit-lamp examination, even of adolescent human eyes, can also reveal fine vitreal fibers (small rudiments of hyaloidal vessels) attaching to the retina between ora and equator [11, 12].

The more the fetal bulb develops, the more the attachment of the vasa hyaloidea onto the retina shifts from the posterior part of the retina into the direction of the ora [13]. Similarly, the demarcation line shifts from zone I to zone III in ROP.

The first examination for ROP should be performed between 4 and 6 weeks of chronological age, respectively [6]. Besides the pathological failure of apoptosis of hyaloidal structure, the peripheral retinal ischemia leads to an increase in the expression of vascular endothelial growth factor (VEGF) that is a critical factor contributing to retinal neovascularization [14-16]. However, the pathologic regression of the hyaloidal vessels would probably remain unaffected by anti-VEGF agents. To prevent or treat suspect ROP on premature infants, it might be necessary to destroy or scar the not yet apoptotic remnants of hyaloidal structures (pseudoretina) attaching to the retina. This may be reached for example by transscleral cryocoagulation or laser photocoagulation and gives room for thoughts on new apoptotic treatments.

In conclusion, the close correlation between persistent hyaloidal vessels, tunica vasculosa lentis, and retrolental fibroplasia is well accepted [17-19]. A similar close correlation with regard to temporally persistent hyaloidal structures, premature growing retinal vessels, and retinopathy of prematurity is only rarely discussed but deserves reconsideration with respect to new treatment possibilities.

\section{References}

1. Pau H (2008) Retinopathy of prematurity: clinic and pathogenesis. Ophthalmologica 222:220-224

2. Déjean CH (1958) Embryplogie du corps vitré. In: Déjean CH, Leplat C (eds) L'embryologie de L 'œil et sa tératologie. Paris, Massom, pp 220-308
3. Cook C, Sulic K, Wright KW (2003) Embryology. In: Wright KW, Spiegel PH (eds) Pediatric Ophthalmology and Strabismus. Springer, Berlin Heidelberg New York

4. Mann I (1964) The development of the human eye. British Editorial Association, London

5. Michaelson IC (1948) The mode of development of the vascular system of the retina with some observations on its significance for certain retinal disease. Trans Ophthalmol Soc UK 58:137-180

6. Ober RR, Palmer EA, Drack AV, Wright KW (2002) Retinopathy of prematurity. In: Wright KW, Spiegel $\mathrm{PH}$ (eds) Pediatric ophthalmology and strabismus. Springer, Berlin Heidelberg New York

7. Jandeck C, Foerster MH (2007) ROP: clinical course and treatment. In: Joussen AM, Gardner TW, Kirchhof B, Ryan SJ (eds) Retinal vascular disease. Springer, Berlin Heidelberg New York

8. McHolm JR, Hartnett ME (2005) Retinopathy of prematurity: current understanding based on clinical trials and animal models. In: Hartnett ME, Trese M, Capone A, Keats GJB, Steidel SN (eds) Pediatric Retina. Lippencott, Williams and Wilkins, Philadelphia

9. Cryotherapy for Retinopathy of Prematurity Cooperative Group (1988) Multicenter trial of cryotherapy of prematurity preliminary results. Arch Ophthalmol 106:471-479

10. Cryotherapy for Retinopathy of Prematurity Cooperative Group (1993) Multicenter trial of cryotherapy of prematurity: 3.5-year outcome structure and function. Arch Ophthalmol 111:339-344

11. Eisner G (1971) Autoptische Spaltlampenuntersuchungen des Glaskörpers. II. Die spaltlampenmikroskopisch sichtbaren Glaskörperstrukturen. Graefes Arch Klin Exp Ophthalmol $182: 23-40$

12. Eisner G (1971) Autoptische Spaltlampenuntersuchungen des Glaskörpers. III. Beziehungen zur Histologie, Biomikroskopie und Klinik. Graefes Arch Klin Exp Ophthalmol 182:23-40

13. Pau H (1969) Die Struktur des Glaskörpers in Beziehung zu Embryonalen Blutgefäßen und Glaskörperrindenzellen. Graefes Arch Klin Exp Ophthalmol 177:261-270

14. Smith LEH (2008) Through the eyes of a child: understanding retinopathy through ROP. The Friedenwald lecture. Invest Ophthalmol Vis Sci 49:5177-5812

15. Robinson GS, Pierce EA, Rook SL, Foley E, Webb R, Smith LE (1996) Oligodeoxynucleotides inhibit retinal neovascularization in a murine model of proliferative retinopathy. Proc Natl Acad Sci USA 93:4851-4656

16. Donahue ML, Phelps DL, Wackins RH, LoMonaco MB, Horowitz S (1996) Retinal vascular endothelial growth factor (VEGF) mRNA expression is altered in relation to neovascularization in oxygen-induced retinopathy. Curr Eye Res 15:175184

17. Terry TL (1942) Extreme prematurity and fibroplasia, overgrowth of persistent vascular sheath behind each crystalline lens. A preliminary report. Am J Ophthalmol 25:203-204

18. Gunn TR (1980) Risk factors in retrolental fibroplasia. Pediatrics 65:1096-1100

19. Reese AB (1946) Persistence and hyperplasy of the primary vitreous (tunica vasculosa lentis or retrolental fibroplasia). Am J Ophthalmol 29:1-24

20. International Committee of the Classification of the Late Stages of Retinopathy of Prematurity (1987) An international classification of the late stages of retinopathy of prematurity. II. The classification of retinal detachment. Arch Ophthalmol 105:908 